\title{
Spatial structure of genetic variability in natural stands of Fagus sylvatica L. (beech) in Italy
}

\author{
STEFANO LEONARDI* \& PAOLO MENOZZI \\ Istituto di Ecologia, Università di Parma, Viale delle Scienze, 43100 Parma, Italy
}

\begin{abstract}
We report an autocorrelation study of 11 enzyme loci detected by starch gel electrophoresis in 14 populations over the Italian biogeographical range of beech (Fagus sylvatica L.). In line with previous studies of beech and other forest tree species a low level of spatial autocorrelation was detected. No correlation between the amount of microspatial structuring of genetic variability in different populations and environmental (latitude, longitude, altitude), structural (mean and standard deviation of tree size) and genetic characteristics (mean expected heterozygosity, mean $F_{\text {IS }}$ ) was found. No significant differences in the amount of spatial structuring seem to exist among loci if low heterozygosity loci are excluded from the analysis.
\end{abstract}

Keywords: allozymes, Fagus sylvatica, forest-tree populations, genetic structure, spatial autocorrelation.

\section{Introduction}

In forest tree populations most genetic variability estimated by enzyme electrophoresis is found at the intrapopulation level (Hamrick \& Godt, 1990; Muona, 1990). This partitioning of genetic variation has been linked to life cycle characteristics (extended life span and long generation time) and mating system traits (pollination and seed dispersal by wind, high outcrossing rate) common to mid to high latitude forest tree species (Loveless \& Hamrick, 1984).

European beech (Fagus sylvatica L.) is no exception to this general pattern (Comps et al., 1990; Müller-Starck et al., 1992). In a survey of 21 Italian populations of beech we confirmed this partitioning of genetic variability and also found that a substantial part of the variation is attributable to the withinsubpopulation component (Leonardi \& Menozzi, 1995).

The study of spatial patterns in genetic variability could lead to new insights into the causes that determine the observed partitioning of variation among and within populations. The introduction of autocorrelation techniques to the study of the spatial distribution of genetic variability (Sokal \& Oden, 1978; Sokal \& Wartenberg, 1983; Sokal et al., 1989; Sokal \& Oden, 1991) stimulated a number of inves-

*Correspondence. tigations in forest tree populations. The descriptive power of the technique, that does not depend on the scale of the spatial structure, has never been questioned. A debate on the limits of autocorrelation in inferring from the observed spatial structure the evolutionary forces that generated it, set the usefulness of the results from this approach within a realistic framework (Slatkin \& Arter, 1991a).

Spatial genetic structure can be the result of the action of several evolutionary processes including isolation in small patches, limited pollen and seed dispersal and selection acting at the microhabitat level. Although it may be unrealistic to expect spatial autocorrelation to assess subtle differences among evolutionary processes, the technique seems quite appropriate to describe the main evolutionary forces affecting a population. Spatial structuring affecting most loci is reasonably interpreted as evidence of migration or processes related to gene flow, whereas significant correlograms for only a few genetic traits can be safely interpreted as a result of drift or selection (Sokal \& Menozzi, 1982).

Few studies on forest tree species have found significant spatial structuring that could be attributed to some specific cause. In Tamarack (Larix laricina) two nearby populations showed striking differences in spatial structuring of alleles explained by the events that followed severe anthropogenic disturbance. One population, re-established by outside sources of seeds, showed random spatial 
assortment of alleles whereas the other, regenerated from individuals surviving the disturbance, showed spatial structuring (Knowles et al., 1992). Strong spatial clumping was reported for Atherosperma moschatum (Shapcott, 1995) but vegetative reproduction and limited pollen and seed dispersal make this a special case in forest tree populations.

In general, evidence is accumulating for a weak spatial structuring of the within-population variability in many forest tree populations. In European beech only a small number of significant autocorrelation values was found in a study of three natural stands in France (Merzeau et al., 1994). Similar results were obtained in other forest tree species: Picea mariana (Knowles, 1991), Acer saccharum (Perry \& Knowles, 1991), Quercus petraea and $Q$. robur (Bacilieri et al., 1994). Studies with intensive sampling of relatively limited areas also revealed scarce spatial structuring in lodgepole pine (Epperson \& Allard, 1989), Picea abies (Leonardi et al., 1996) and Turkey oak (Berg \& Hamrick, 1995).

Few studies have investigated spatial structuring within populations in many localities for an adequate number of loci over a relatively large geographical area. In the present paper we report an autocorrelation study of 11 loci in 14 populations over the Italian biogeographical range of beech. The evaluation of microspatial structuring of genetic variability in many different populations allows the study of the relationship between autocorrelation parameters and environmental (latitude, longitude, altitude), structural (mean and standard deviation of tree size) and genetic characteristics (mean expected heterozygosity, mean $F_{\text {IS }}$ ) found in different localities. Studying the association of any given locus characteristic with autocorrelation parameters allows the testing of the frequently reported differences in spatial structuring among genetic traits.

\section{Materials and methods}

\section{Studied populations, sampling and electrophoretic analysis}

Dormant buds were collected from individual trees from 14 Italian populations (Table 1). Their population genetic parameters were reported in a study of genetic variability of European beech in Italy based on a large number of populations (Leonardi \& Menozzi, 1995). The trees were sampled from localities well within the species biogeographical range in Italy. All the stands had been coppiced up to less than a generation ago.
Trees at least $2 \mathrm{~m}$ apart were sampled to avoid the replicate sampling of coppice-sprouted individuals. Coordinates of each tree were determined using an ultrasound electronic device (Sonin 250) and a compass. The diameter of each tree was measured at breast height.

Eleven loci were assayed by means of horizontal starch gel electrophoresis and used to determine the multilocus genotype of each tree: $6 P G D-A$ (EC 1.1.1.44), $A C O-A$ and $A C O-B$ (EC 4.2.1.3) $D L A-A$ (EC 1.8.1.4), GOT-A (EC 2.6.1.1), GPI-B (EC 5.3.1.9), IDH- $A$ (EC 1.1.1.42), $M D H-A$ and $M D H-B$ (EC 1.1.1.37), PER-B (EC 1.11.1.7), and $S K D H-A$ (EC 1.1.1.25). Loci $A C O-A$ and $A C O-B$ were not analysed in three populations (ABE, PIS and PNA). Electrophoresis procedures and gene frequencies have been reported elsewhere (Leonardi \& Menozzi, 1995).

\section{Spatial autocorrelation analysis}

Spatial autocorrelation was performed according to Cliff \& Ord (1973) on 'nominal' (genotype) data. An ad hoc computer program was written in the $\mathrm{C}$ language and run on a Sun SPARCstation 10/20. Distances between all possible pairs of trees were calculated, sorted and assigned to a distance class. The analysis was carried out using two different criteria to set distance class limits. According to the first criterion five distance classes with variable distance limit values having the same number of pairs in all classes were chosen (Table 2). The second criterion implied carrying out the analysis for distances less than $30 \mathrm{~m}$, with fixed $(10 \mathrm{~m})$ distance intervals (Table 2).

The standard normal deviate (SND) was computed as the difference between the frequency of observed and expected genotype pairs in each distance class standardized for the standard deviation for the class. Expected genotype pairs and standard deviations were calculated from genotype frequencies in the total population under the null hypothesis of random spatial arrangement of genotypes in each distance class and nonfree sampling (Cliff \& Ord, 1973; Epperson \& Allard, 1989).

Pairs of plants with the same genotype are called like genotype pairs, whereas those with different genotypes are called unlike genotype pairs. Clumped distributions of genotypes cause significant excesses (significant positive SNDs) of like genotype pairs or defects (significant negative SNDs) of unlike genotype pairs in first distance classes. This seems to justify focusing the analysis on the first distance classes.

(c) The Genetical Society of Great Britain, Heredity, 77, 359-368. 
Table 1 Environmental and biological characteristics of sampled stations

\begin{tabular}{|c|c|c|c|c|c|c|c|c|c|}
\hline Population & Abbr. & $\begin{array}{c}\text { Alt. } \\
\text { (m a.s.l.) }\end{array}$ & Lat. & Long. & $\begin{array}{l}\text { Sample } \\
\text { size }\end{array}$ & $\begin{array}{l}\text { Mean tree } \\
\text { diameter } \\
(\mathrm{cm})\end{array}$ & $\begin{array}{c}\text { SD } \\
\text { diameter } \\
(\mathrm{cm})\end{array}$ & $\begin{array}{c}\text { Mean } \\
H\end{array}$ & $\begin{array}{c}\text { Mean } \\
F_{\text {IS }}\end{array}$ \\
\hline Abetone (PT) & $\mathrm{ABE}$ & 1489 & $44^{\circ} 08^{\prime}$ & $10^{\circ} 42^{\prime}$ & 147 & 15.680 & 12.026 & 0.192 & 0.384 \\
\hline For. Cansiglio (PN) & CAN & 1230 & $46^{\circ} 10^{\prime}$ & $12^{\circ} 20^{\prime}$ & 119 & 28.714 & 9.861 & 0.217 & 0.080 \\
\hline Val Cervo (VC) & CER & 1040 & $45^{\circ} 45^{\prime}$ & $7^{\circ} 50^{\prime}$ & 100 & 25.550 & 16.644 & 0.154 & 0.096 \\
\hline Entracque $(\mathrm{CN})$ & ENT & 1280 & $44^{\circ} 15^{\prime}$ & $7^{\circ} 20^{\prime}$ & 85 & 15.635 & 9.620 & 0.206 & 0.036 \\
\hline Val Giudicarie (TN) & GIU & 1250 & $46^{\circ} 08^{\prime}$ & $10^{\circ} 45^{\prime}$ & 100 & 13.900 & 6.477 & 0.154 & 0.090 \\
\hline M. Pisanino (LU) & PIS & 1295 & $44^{\circ} 08^{\prime}$ & $10^{\circ} 13^{\prime}$ & 99 & 16.170 & 14.473 & 0.176 & 0.271 \\
\hline P.so Pradarena (LU) & PNA & 1425 & $44^{\circ} 23^{\prime}$ & $10^{\circ} 18^{\prime}$ & 149 & 16.308 & 9.329 & 0.155 & 0.116 \\
\hline Monte Pollino (PZ) & POL & 1360 & $39^{\circ} 56^{\prime}$ & $16^{\circ} 41^{\prime}$ & 101 & 21.060 & 9.382 & 0.189 & 0.098 \\
\hline Aspromonte (RC) & REC & 1350 & $38^{\circ} 08^{\prime}$ & $15^{\circ} 54^{\prime}$ & 91 & 22.100 & 12.464 & 0.205 & 0.087 \\
\hline Serra S. Bruno (CZ) & SER & 1310 & $38^{\circ} 33^{\prime}$ & $16^{\circ} 24^{\prime}$ & 124 & 22.952 & 13.884 & 0.199 & 0.097 \\
\hline Sicilia (ME) & SIC & 1550 & $37^{\circ} 57^{\prime}$ & $14^{\circ} 51^{\prime}$ & 93 & 19.730 & 7.759 & 0.205 & 0.132 \\
\hline Passo Tanamea (UD) & TAN & 800 & $46^{\circ} 15^{\prime}$ & $13^{\circ} 25^{\prime}$ & 98 & 19.490 & 9.029 & 0.140 & 0.110 \\
\hline Foresta Umbra (FG) & UMB & 800 & $41^{\circ} 49^{\prime}$ & $16^{\circ} 03^{\prime}$ & 93 & 32.640 & 25.946 & 0.188 & 0.101 \\
\hline Monte Vulture (PZ) & VUL & 968 & $40^{\circ} 56^{\prime}$ & $15^{\circ} 36^{\prime}$ & 120 & 39.575 & 23.236 & 0.210 & 0.123 \\
\hline
\end{tabular}

Abbr., abbreviation; Alt., altitude; Lat., latitude; Long., longitude; HSD, standard deviation; m a.s.l., m above sea level; $H$, heterozygosity.

Table 2 Upper limits of distance classes set to obtain the same number of pairs in all classes (first criterion) and the number of pairs in fixed distance classes (second criterion)

\begin{tabular}{|c|c|c|c|c|c|c|c|c|}
\hline \multirow[b]{2}{*}{ Pop. } & \multicolumn{5}{|c|}{$\begin{array}{l}\text { First criterion - upper limit }(\mathrm{m}) \\
\text { Distance class }\end{array}$} & \multicolumn{3}{|c|}{$\begin{array}{c}\text { Second criterion - no. of pairs } \\
\text { Distance class }\end{array}$} \\
\hline & 1 & 2 & 3 & 4 & 5 & $0-10 \mathrm{~m}$ & $10-20 \mathrm{~m}$ & $20-30 \mathrm{~m}$ \\
\hline $\mathrm{ABE}$ & 48.0 & 101.3 & 181.1 & 289.5 & 527.9 & 69 & 144 & 135 \\
\hline CAN & 77.0 & 143.3 & 256.8 & 382.2 & 554.5 & 112 & 183 & 196 \\
\hline CER & 60.7 & 132.0 & 212.3 & 310.0 & 529.1 & 126 & 173 & 185 \\
\hline ENT & 31.9 & 57.7 & 84.7 & 116.6 & 205.4 & 158 & 246 & 250 \\
\hline GIU & 63.8 & 139.8 & 239.6 & 356.3 & 601.2 & 120 & 171 & 159 \\
\hline PIS & 36.0 & 79.6 & 148.5 & 244.7 & 538.8 & 78 & 103 & 98 \\
\hline PNA & 34.9 & 72.8 & 119.8 & 178.1 & 506.1 & 117 & 247 & 217 \\
\hline POL & 66.5 & 130.2 & 216.3 & 321.2 & 529.3 & 96 & 159 & 168 \\
\hline REC & 66.8 & 137.9 & 210.5 & 308.5 & 549.3 & 91 & 133 & 147 \\
\hline SER & 60.9 & 116.9 & 195.6 & 295.0 & 476.0 & 141 & 211 & 243 \\
\hline SIC & 61.5 & 114.5 & 146.4 & 198.0 & 379.7 & 79 & 152 & 146 \\
\hline TAN & 59.0 & 154.4 & 286.3 & 441.2 & 583.8 & 83 & 177 & 197 \\
\hline UMB & 76.8 & 144.4 & 217.5 & 327.3 & 509.9 & 63 & 131 & 120 \\
\hline VUL & 55.3 & 118.1 & 209.1 & 339.5 & 598.4 & 78 & 143 & 146 \\
\hline
\end{tabular}

In agreement with previous studies (Epperson \& Allard, 1989), SNDs with less than one expected genotype pair were not considered in the computations.

Differences in the numbers of significant positive cases among populations or loci have been tested by $\chi^{2}$. Given the nonindependence of SNDs for geno- types at the same locus in one population, we considered at most one significant SND per locus.

An autocorrelation analysis that produced 'allelic' correlograms was performed using the SAAP program developed by Wartenberg (1989) for the analysis of allele frequencies. In this analysis genetic data were coded such that single trees received allele 
frequency values of $1,0.5$, or 0 for each allele at every locus according to its appropriate gene count. For each locus only the two most frequent alleles were considered. Moran's I (Cliff \& Ord, 1973; Sokal \& Oden, 1978) was estimated for each of the five distance classes defined according to the first criterion previously defined for setting distance classes.

To gain insight into the relationship between autocorrelation and heterozygosity, computer simulations of an isolation-by-distance process were carried out following Sokal \& Wartenberg (1983) and Sokal \& Jacquez (1991). Each simulation produced a grid made up of $441(21 \times 21)$ individuals carrying 11 loci each with two alleles. Genotypes were assigned to each individual to obtain increasing heterozygosities from $H \sim 0.01$ for locus 1 to $H \sim 0.50$ for locus 11 . Once per generation each individual was replaced by one offspring from parents chosen at random from the 48 nearest neighbours. The simulation was carried out for 25 generations. One hundred grids were generated. The proportions of the 100 replicates that yielded significant positive SNDs for like genotypes were counted.

It should be noted that in these simulations the same reproduction event involves all loci of a tree independent of their heterozygosities, so that similar patterns of genetic spatial structuring should be produced for all loci.

Expected heterozygosities and $F_{1 \mathrm{~S}}$ values for simulated and observed data were calculated according to Nei (1987) and statistical computations were carried out using the SAS statistical package (SAS Institute, 1985).

\section{Results}

\section{Spatial structure in Italian beech}

For 'nominal' correlograms with equal numbers of pairs in each distance class a total of 5590 SNDs were computed; of these only the 4329 with expected frequencies greater than 1 were used in the analysis.

For like genotype pairs 38 significant positive SNDs out of a total of 330 (11.5 per cent) were found in the first distance class (Fig. 1), a proportion higher than that expected ( 2.5 per cent $)$ from a type 1 statistical error. Positive significant cases decreased in further distance classes (6.6 per cent, 2.5 per cent, 2.9 per cent and 4.2 per cent in the second, third, fourth and fifth classes, respectively).

As expected, a symmetrical trend was found for unlike genotype pairs: out of 545 SNDs 37 (6.8 per cent) were negative and significant in the first distance class. Decreasing proportions were found for further distance classes (2.9 per cent, 2.0 per cent, 3.5 per cent and 1.8 per cent in the second, third, fourth and fifth classes).

The analysis for 'nominal' correlograms for distances of 10,20 and $30 \mathrm{~m}$ with variable numbers of pairs revealed essentially the same decreasing pattern of significance: from 6 per cent for the first to 2 per cent for the third distance class for like genotype pairs and from 6 per cent for the first to 2 per cent for the third distance class for unlike genotype pairs.

For 'allelic' correlograms we found decreasing significance trends with 30 (21 per cent) significant values for Moran's $I$ out of 141 computed in the first distance class, 19 (13 per cent) in the second, and 11 (7.8 per cent), 10 (7.1 per cent) and 11 ( 7.8 per cent) in the following classes.

We carried out the analysis using both 'allelic' and 'nominal' correlograms following a recent trend in forest tree autocorrelation studies (Merzeau et al., 1994; Bacilieri et al., 1994). In general, for a given population, the two statistics revealed significant results for the same loci although fewer loci showed spatial structuring by 'allelic' than by 'nominal' correlograms. Simulation work has recently shown the different power of the two statistics (Epperson, 1995). 'Allelic' correlograms require a larger sample size to detect significant spatial structures. In the rest of this paper we report only data for 'nominal' correlograms.

\section{Spatial structure in different populations}

A comparison of autocorrelation statistics among populations was carried out to investigate the existence of the effect of either the environmental or biological characteristics of the different populations on the spatial structuring of genetic variability.

For distance classes set to obtain the same number of pairs in all classes (first criterion), the number of significant SNDs is low in all populations with a rather large variation among locations (Table 3 ). The number of significant positive cases for like genotypes in the first distance class varies from six in Val Cervo (CER) to only one in five other locations (PIS, REC, TAN, UMB, SIC). Significant cases decrease in further distance classes. A similar pattern was found for significant negative cases for unlike genotypes.

Essentially the same results were obtained for fixed shorter distances of up to $30 \mathrm{~m}$ (second criter- 


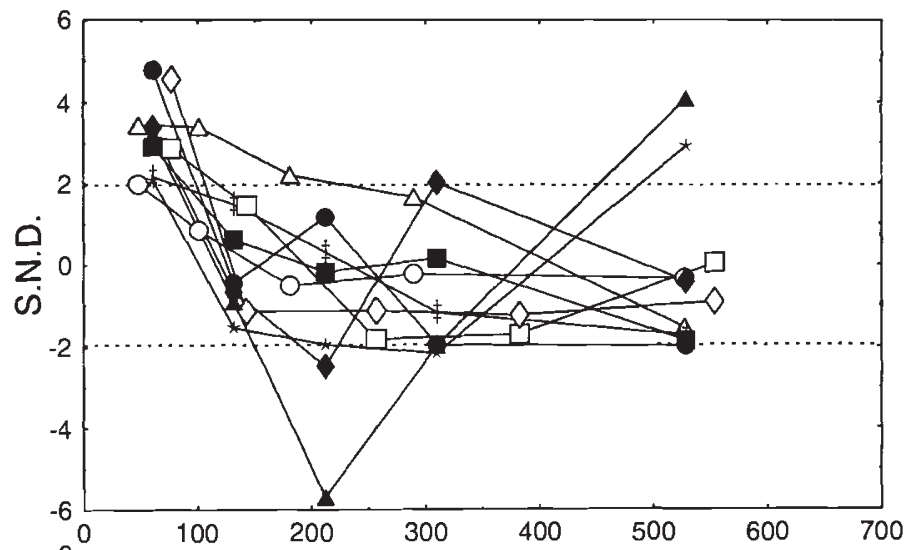

O ABE IDH-A 100/100-100/100

$\triangle$ ABE PER-B 100/100-100/100

$\square$ CAN ACO-B 90/100-90/100

$\checkmark$ CAN SKDH-A 100/110-100/110

- CER ACO-A 90/100-90/100

- CER ACO-A 100/100-100/100

- CER GOT-A 100/100-100/100

- CER IDH-A 100/110-100/110

* CER PER-B 100/110-100/110

$\ddagger$ CER SKDH-A 90/100-90/100

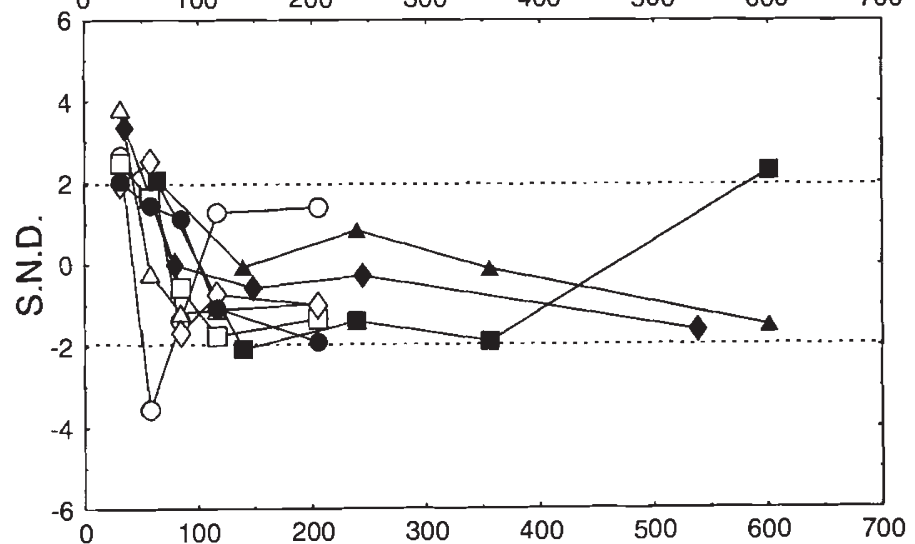

O ENT ACO-A 100/100-100/100

$\triangle$ ENT DIA-A 100/110-100/110

$\square$ ENT GOT-A 102/102-102/102

$\diamond$ ENT PER-B 100/110-100/110

- ENT SKDH-A 100/100-100/100

- GIU PER-B 100/100-100/100

- GIU SKDH-A 90/100-90/100

- PIS PER-B 100/110-100/110

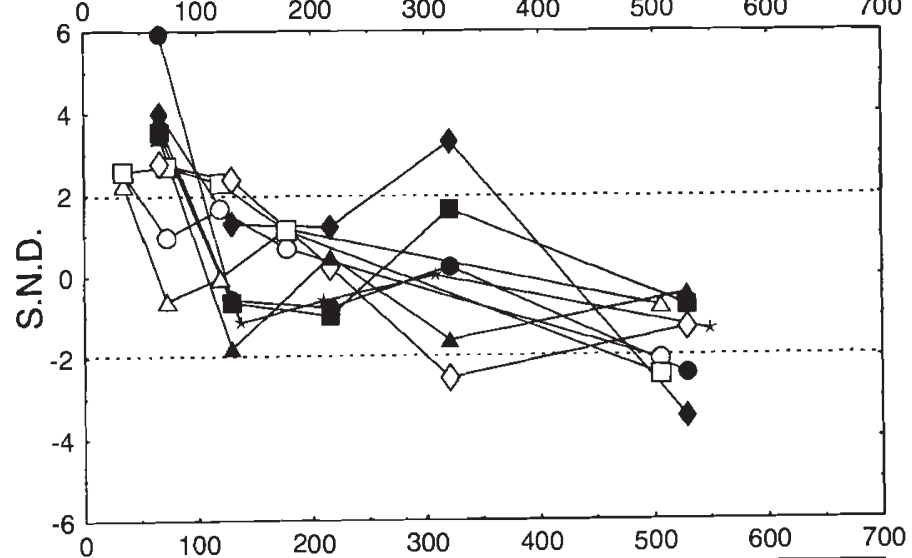

O PNA IDH-A 100/100-100/100

$\triangle$ PNA IDH-A 110/110-110/110

$\square$ PNA PER-B 100/100-100/100

$\diamond$ POL $A C O-B \quad 100 / 100-100 / 100$

- POL $A C O-B \quad 110 / 110-110 / 110$

- POL ACO-A 100/100-100/100

- POL IDH-A 100/100-100/100

- POL PER-B 100/100-100/100

$\star$ REC GOT-A 102/102-102/102

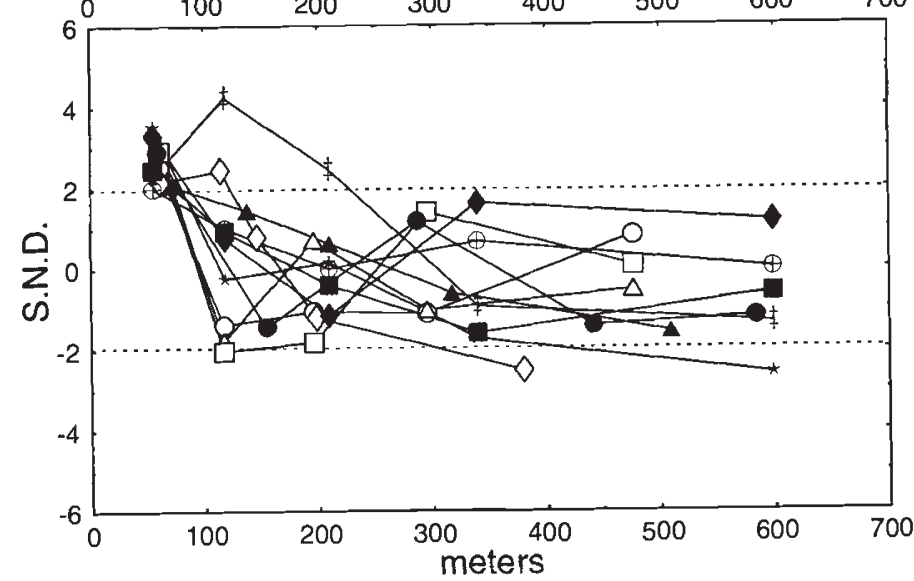

O SER ACO-B 90/100-90/100

$\triangle$ SER GPI-B 95/100-95/100

$\square$ SER PER-B 100/110-100/110

$\diamond$ SIC DIA-A 100/100-100/100

- TAN GPI-B 95/100-95/100

- UMB GOT-A 100/100-100/100

- VUL ACO-A 100/100-100/100

- VUL GOT-A 100/100-100/100

* VUL GOT-A 102/102-102/102

$\ddagger$ VUL PER-B 100/110-100/110

$\oplus$ VUL SKDH-A 100/100-100/100

Fig. 1 The 38 correlograms with a significant SND in the first distance class. See keys for population, locus and genotype identification. Five per cent significance thresholds indicated by horizontal dashed lines. Population abbreviations as Table 1.

(c) The Genetical Society of Great Britain, Heredity, 77, 359-368. 
ion, Table 3). A high correlation $(r=0.77 ; n=14$; $P=0.001$ ) was found between the significant cases observed in the first distance class, set according to the first criterion, and the total number of significant cases obtained for fixed distance classes up to $30 \mathrm{~m}$. In fact, with the exception of one population (PNA), the highest proportion of significant cases was found in the $0-10 \mathrm{~m}$ class. It is worth noting that for almost half of the populations as many significant statistics were also found in the $10-20 \mathrm{~m}$ class as in the $0-10$ m class.

No significant correlation was found between environmental (latitude, longitude, altitude), struc- tural (mean and standard deviation of tree size), and genetic (mean expected heterozygosity, mean $F_{\text {IS }}$ ) characteristics of different stations and the number of significant $S N D$ s in the first distance class of both analyses.

\section{Spatial structure of different loci}

A comparison of autocorrelation statistics among loci was carried out to evaluate differences among genetic markers in tracking spatial structuring.

Table 3 was rearranged to show the percentage of significant cases for like genotypes for a given locus

Table 3 Percentage of significant positive SNDs for like genotypes, with respect to the total number of cases with expected frequencies greater than one, for each station

\begin{tabular}{|c|c|c|c|c|c|c|c|c|}
\hline \multirow[b]{2}{*}{ Pop. } & \multicolumn{8}{|c|}{ Distance classes } \\
\hline & 1 & 2 & 3 & 4 & 5 & $0-10 \mathrm{~m}$ & $10-20 \mathrm{~m}$ & $20-30 \mathrm{~m}$ \\
\hline $\mathrm{ABE}$ & 10.5 & 10.5 & 5.3 & 10.5 & 5.3 & 0.0 & 0.0 & 0.0 \\
\hline CAN & 7.1 & 10.7 & 0.0 & 3.6 & 0.0 & 5.3 & 0.0 & 0.0 \\
\hline CER & 26.1 & 8.7 & 0.0 & 4.3 & 13.0 & 17.6 & 11.8 & 17.6 \\
\hline ENT & 18.5 & 7.4 & 3.7 & 0.0 & 0.0 & 25.0 & 9.1 & 0.0 \\
\hline GIU & 8.3 & 4.2 & 4.2 & 0.0 & 8.3 & 5.6 & 5.6 & 5.9 \\
\hline PIS & 5.6 & 5.6 & 0.0 & 0.0 & 6.2 & 7.7 & 7.7 & 0.0 \\
\hline PNA & 15.0 & 10.0 & 5.0 & 5.0 & 15.0 & 0.0 & 12.5 & 0.0 \\
\hline POL & 20.8 & 4.2 & 0.0 & 4.2 & 0.0 & 21.1 & 20.0 & 10.5 \\
\hline REC & 4.0 & 4.0 & 0.0 & 8.0 & 0.0 & 11.1 & 0.0 & 0.0 \\
\hline SER & 11.1 & 3.7 & 0.0 & 0.0 & 3.7 & 20.0 & 0.0 & 21.1 \\
\hline SIC & 3.8 & 3.8 & 0.0 & 4.0 & 0.0 & 5.3 & 5.3 & 0.0 \\
\hline TAN & 4.3 & 0.0 & 4.3 & 0.0 & 0.0 & 6.2 & 6.2 & 0.0 \\
\hline UMB & 4.3 & 8.7 & 4.3 & 0.0 & 4.3 & 6.2 & 5.6 & 0.0 \\
\hline VUL & 21.7 & 8.7 & 9.1 & 0.0 & 4.5 & 5.0 & 5.0 & 9.5 \\
\hline
\end{tabular}

Table 4 Percentage of significant positive SNDs for like genotypes, with respect to the total number of cases with expected frequencies greater than one, for each locus

\begin{tabular}{|c|c|c|c|c|c|c|c|c|}
\hline \multirow[b]{2}{*}{ Locus } & \multicolumn{8}{|c|}{ Distance classes } \\
\hline & 1 & 2 & 3 & 4 & 5 & $0-10 \mathrm{~m}$ & $10-20 \mathrm{~m}$ & $20-30 \mathrm{~m}$ \\
\hline $6 P G D-A$ & 0.0 & 0.0 & 0.0 & 0.0 & 0.0 & 6.2 & 0.0 & 0.0 \\
\hline$A C O-B$ & 11.4 & 17.1 & 0.0 & 0.0 & 5.7 & 10.7 & 6.9 & 6.9 \\
\hline$A C O-A$ & 19.2 & 11.5 & 3.8 & 0.0 & 7.7 & 23.8 & 14.3 & 4.8 \\
\hline$D L A-A$ & 8.7 & 8.7 & 4.3 & 4.3 & 4.3 & 5.6 & 0.0 & 0.0 \\
\hline GOT-A & 15.0 & 0.0 & 0.0 & 2.5 & 2.6 & 11.5 & 3.6 & 10.7 \\
\hline$G P I-B$ & 9.1 & 4.5 & 0.0 & 0.0 & 4.5 & 13.3 & 0.0 & 0.0 \\
\hline$I D H-A$ & 13.2 & 5.3 & 5.3 & 2.6 & 2.7 & 0.0 & 5.9 & 2.9 \\
\hline$M D H-B$ & 0.0 & 0.0 & 0.0 & 3.7 & 0.0 & 10.5 & 4.5 & 9.1 \\
\hline$M D H-A$ & 0.0 & 0.0 & 0.0 & 7.1 & 0.0 & 0.0 & 0.0 & 0.0 \\
\hline$P E R-B$ & 20.9 & 11.6 & 7.0 & 4.7 & 4.7 & 18.8 & 18.8 & 6.2 \\
\hline$S K D H-A$ & 19.2 & 7.7 & 4.0 & 7.7 & 12.0 & 9.5 & 4.3 & 5.3 \\
\hline
\end{tabular}


over all populations (Table 4). High variability among loci was apparent and, not surprisingly given the results reported in Table 3, the first distance class had the greatest proportion of significant statistics. The number of significant positive cases for like genotypes in the first distance class varied from nine for locus $P E R-B$ to zero for three other loci (6PGD-A, $M D H-A, M D H-B)$. Significant cases decreased in further distance classes. A similar pattern was found for significant negative cases for unlike genotypes.

With few exceptions ( $A C O-B$ and $D I A-A)$ a sharp decrease of the number of significant SNDs, already clear in the second distance class, can be observed at greater distances. This result is confirmed by the analysis for fixed shorter distances of up to $30 \mathrm{~m}$ (Table 4). With the exception of one locus $(I D H-A)$ the greatest proportion of significant cases was found in the $0-10 \mathrm{~m}$ class and for only one locus $(P E R-B)$ did the class $10-20$ show as many cases.

\section{Spatial structuring among populations and loci}

A summary of our results is presented in Fig. 2 where we report for all populations the number of like genotypes for each locus that had a significant
SND in the first distance class. In only four cases was more than one SND significant for a locus in a given population.

Visual inspection of Fig. 2 suggested that some loci were spatially structured in most populations, whereas others showed almost no autocorrelation. Locus PER-B had at least one significant SND in nine out of 14 populations, whereas three other loci had no populations with a significant SND $(M D H-B$, $M D H-A, 6 P G D-A)$. Differences among populations in spatial structuring are less clear. A quantitative evaluation of the spatial structuring amongst populations and loci could be obtained by computing a heterogeneity $\chi^{2}$ for the loci with at least one significant SND in the 14 populations and a second $\chi^{2}$ for the populations with at least one significant SND at the 11 loci. No differences were found among populations $\left(\chi_{13}^{2}=17.45 ; P=0.18\right)$, whilst the visual impression of a variable degree of structuring among loci was confirmed $\left(\chi_{10}^{2}=19.07 ; P=0.02\right)$.

\section{Spatial structuring and genetic variability}

To evaluate the effect of the variability and the genetic structure of a given locus on its spatial structuring we computed the correlation between the number of significant SNDs in the first distance class
Fig. 2 Numbers of significant positive SNDs for like genotypes with expected frequencies greater than one, for each locus and population.

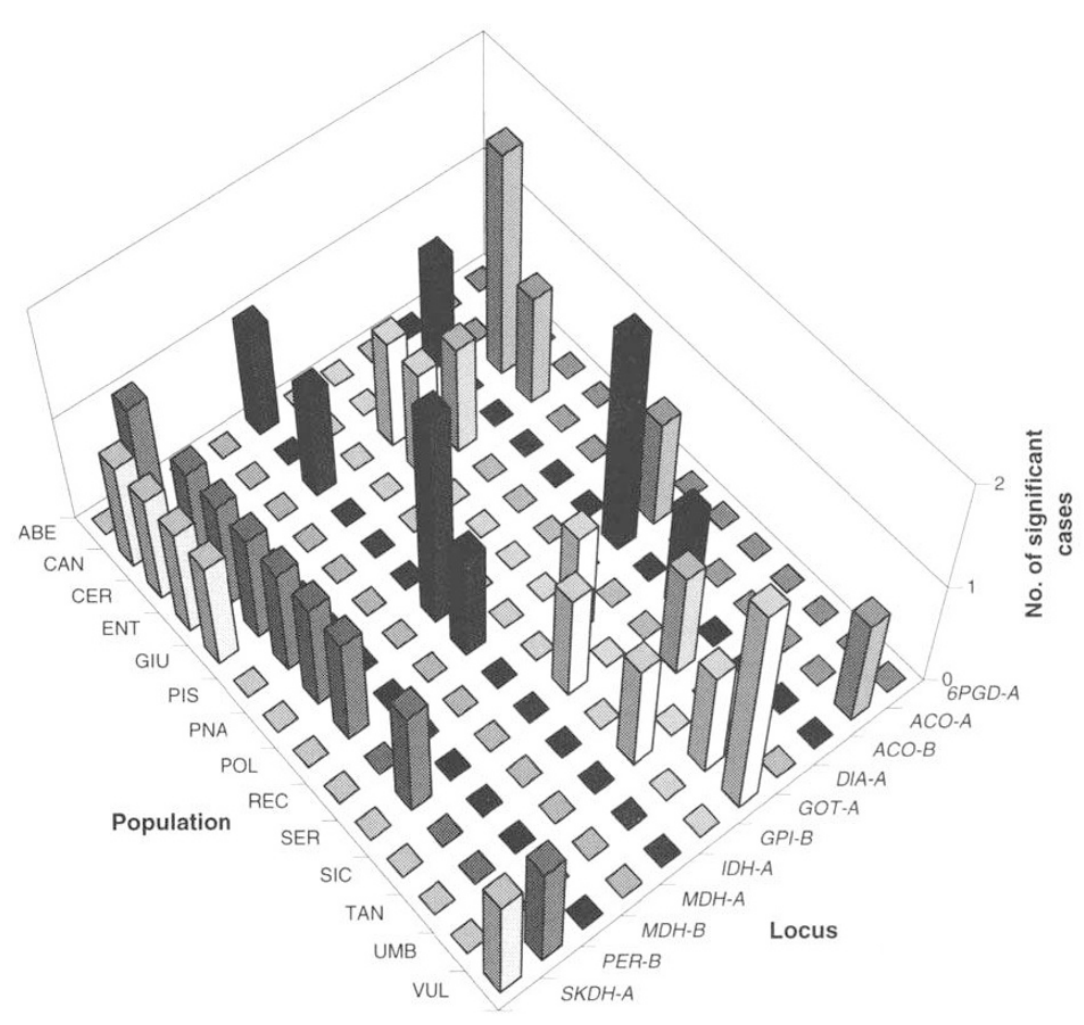

(c) The Genetical Society of Great Britain, Heredity, 77, 359-368. 
and the mean expected heterozygosity and mean homozygote excess $\left(F_{\text {IS }}\right)$ for a given locus over all populations. A significant association was found between spatial structuring and expected heterozygosity $(r=0.79 ; n=11 ; P=0.004)$, whereas no correlation was detected between spatial structuring and mean $F_{1 S}(r=0.42 ; n=11 ; P=0.20)$.

In order to gain further insight a simulation experiment was carried out. In spatial genetic structures built under an isolation-by-distance mechanism the relationship is a step function as clearly seen in Fig. 3. In fact if we compute the correlation between heterozygosity and amount of spatial structuring separately for loci with lower $(H<0.11)$ and higher $(H>0.11)$ variability the relationship is not significant $(r=0.27 ; n=5 ; P=0.62$, and $r=0.18 ; n=6$; $P=0.77$, respectively, Fig. 3 ). The correlation between heterozygosity and spatial structuring computed on the complete data set seems a classical example of misleading correlation. Contrary to what was previously found, if loci with heterozygosities less than 0.11 were excluded no significant differences existed in the percentage of significant autocorrelations among loci $\left(\chi_{5}^{2}=5.138 ; P=0.40\right)$.

\section{Discussion}

Autocorrelation analysis carried out on distance classes of variable lengths containing the same number of trees (first criterion) and on fixed distance limits (second criterion) yielded concordant results. The relatively large variation in class distance limits defined according to the first criterion (Table 2) is in part the result of size differences between trees in different populations (range of

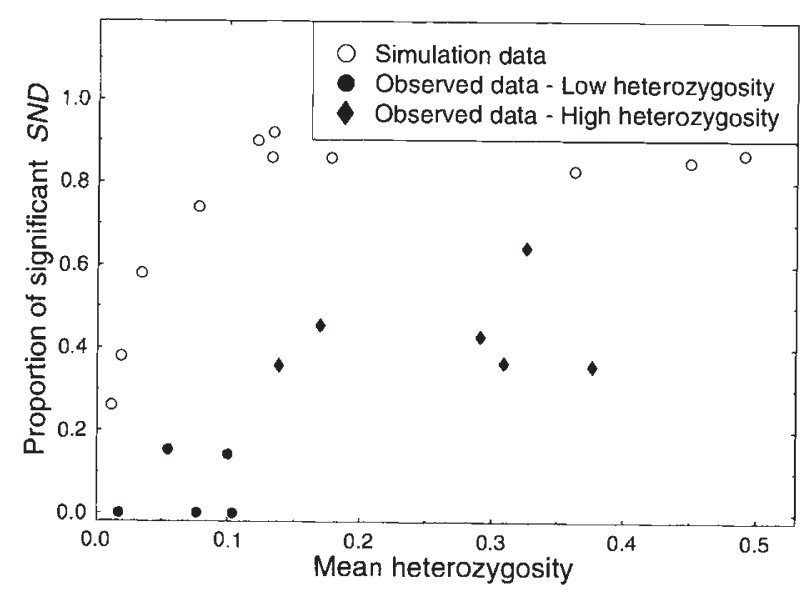

Fig. 3 Relationship between heterozygosity and amount of spatial structuring for loci with lower $(H<0.11)$ and higher $(H>0.11)$ variability and for simulated data. mean diametres at $1.3 \mathrm{~m}$ height: $14-40 \mathrm{~cm}$; $F_{53,1533}=31.73 ; P=0.0001$ ), which leads to a lower sampling density for populations made up of larger trees. The mean of the first two nearest-neighbour distances is significantly correlated with tree size $(r=0.10 ; n=1547 ; P=0.0001)$.

The analysis of 11 loci for a large number of populations spanning the Italian Peninsula confirms the low level of spatial structuring reported in the literature for forest trees. To our knowledge only one autocorrelation study has been published for beech (Merzeau et al., 1994). In two French populations only five out of 35 and two out of 20 significant SNDs were found. Similar patterns have been found for the coniferous species Pinus contorta (Epperson \& Allard, 1989), Picea mariana (Knowles, 1991), Picea abies (Leonardi et al., 1996) and for the broadleaved species Acer saccharum (Perry \& Knowles, 1991; Young \& Merriam, 1994), Quercus petraea and Q. robur (Bacilieri et al., 1994). In this study most genotypes were apparently randomly located within the population. In the first distance class, which was the most informative for the spatial structuring of genetic traits, only about 10 per cent of like genotypes were associated with statistically significant clusters.

The diameter of the patch size has been measured as the distance at which the correlogram crosses the $X$-axis (Sokal \& Wartenberg, 1983). This measure, probably reasonable for square patches, has been reported to overestimate patches of irregular shape (Berg \& Hamrick, 1995). Patch size was estimated as the minimum distance at which statistically significant correlograms showed values below the chosen probability threshold. In the analysis for fixed short distances, patch size for different populations and loci was never more than $30 \mathrm{~m}$. In two French populations, Merzeau et al. (1994) observed similar values. A patch size of $28 \mathrm{~m}$ was reported for Quercus laevis (Berg \& Hamrick, 1995). In $Q$. petraea and $Q$. robur the greatest values of Moran's $I$ were found in the $0-10 \mathrm{~m}$ class, with almost no significant values present in the $10--20 \mathrm{~m}$ class (Bacilieri et al., 1994).

In forest trees, given the generally weak spatial structuring, it is difficult to find the determinants of the spatial distribution of genotypes. Whether selection or isolation-by-distance is the prevailing cause of spatial structuring and whether autocorrelation is capable of distinguishing between these two categories of causes has been discussed at length (Slatkin \& Arter, 1991a,b; Sokal \& Oden, 1991).

We found no significant differences in spatial structuring among populations. Although only 
limited variation in environments exists among localities, this result could be seen as an indication of the relative importance of environmental characteristics in the spatial arrangements of genotypes in Italian beech. Given the difference in average tree size among populations it could be inferred that, at least for mature individuals, tree size (and hence tree age) does not seem to affect spatial structuring.

The analysis by loci gave quite different results if only those traits with higher variability $(\tilde{\mathrm{H}}>0.11)$ in the whole data set were considered. Cliff \& Ord (1973) found that the assumptions for significance tests for autocorrelation statistics do not hold for traits with frequencies less than 0.20. Sokal \& Wartenberg (1983) found no effect of variability on autocorrelation statistics only for traits with frequencies above 0.10 . In our simulation experiment we found a lower threshold $(\sim 0.05$ which approximately corresponds to $H$-values of $\sim 0.10)$. This probably depends on the limited size of our simulations that, like in a census, consider all individuals in their computations.

Given the sample nature of our observed data it is not surprising to find a lower proportion of significant SNDs than in the simulated data. We can conclude that loci with low variability should not be considered in the analysis. If we follow this recommendation no significant difference is found among loci.

\section{Acknowledgements}

The study was supported by the Italian National Research Council (CNR): special project RAISA (sub-project 2, paper no. 2515). We are grateful to R. Giannini for having shared with us his knowledge of Italian beech. We thank the members of the Italian Forest Service (Corpo Forestale dello Stato), S. Baroni, G. Bucci and M. Naldi for assistance during sampling. We are also grateful to V. Rossi and $M$. Borghetti for helpful comments on the manuscript.

\section{References}

BACILIERI, R., LABBE, T. AND KREMER, A. 1994. Intraspecific genetic structure in a mixed population of Quercus petraea (Matt.) Leibl and Q. robur L. Heredity, 73, 130-141.

BERG, E. E. AND HAMR1CK, J. L. 1995. Fine-scale genetic structure of a Turkey oak forest. Evolution, 49, $110-120$.

ClifF, A. D. AND ORD, J. K. 1973. Spatial Autocorrelation. Monographs in Spatial and Environmental System Analysis. Pion, London.
COMPS, B., THIÉBAUT, B., PAULE, L., MERZEAU, D. AND LETOUZEY, J. 1990. Allozymic variability in beechwoods (Fagus sylvatica L.) over central Europe: spatial differentiation among and within populations. Heredity, 65 , 407-417.

EPPERSON, B. K. 1995. Fine-scale spatial structure: correlations for individual genotypes differ from those for local gene frequencies. Evolution, 49, 1022-1026.

EPPERSON, B. K. AND ALLARD, R. W. 1989. Spatial autocorrelation analysis of the distribution of genotypes within populations of lodgepole pine. Genetics, 121, 369-377.

HAMRICK, J. L. AND GODT, M. J. w. 1990. Allozyme diversity in plant species. In: Brown, A. H. D., Clegg, M. T., Kahler, A. L. and Weir, B. S. (eds) Plant Population Genetics, Breeding, and Genetic Resources, pp. 43-63. Sinauer, Sunderland, MA.

KNOWLES, P. 1991. Spatial genetic structure within two natural stands of Black Spruce (Picea mariana (Mill.) B.S.P.). Silvae Genet., 40, 13-19.

KNOWLES, P., PERRY, D. J. AND FORSTER, H. A. 1992. Spatial genetic structure in two tamarack [Larix laricina $(\mathrm{Du}$ Roi) K. Koch] populations with differing establishment histories. Evolution, 46, 572-576.

LEONARD1, S. AND MENOZZI, P. 1995. Genetic variability of Fagus sylvatica L. in Italy: the role of postglacial recolonization. Heredity, 75, 35-44.

LEONARDI, S., RADD1, s. AND BORGHETT1, M. 1996. Spatial autocorrelation of allozyme traits in a Norway spruce (Picea abies) population. Can. J. Forest Res., 26, 63-71.

LOVELESS, M. D. AND HAMRICK, J. L. 1984. Ecological determinants of genetic structure in plant populations. Ann. Rev. Ecol. Syst., 15, 65-95.

MERZEAU, D., COMPS, B., THIÉBAUT, B., CUGUEN, J. AND LETOUZEY, J. 1994. Genetic structure of natural stands of Fagus sylvatica L. (beech). Heredity, 72, 269-277.

MÜLLER-STARCK, G., BARADAT, PH. AND BERGMANN, F. 1992. Genetic variation within European tree species. New Forests, 6, 23-47.

muona, o. 1990. Population genetics in forest tree improvement. In: Brown, A. H. D., Clegg, M. T., Kahler, A. L. and Weir, B.S. (eds) Plant Population Genetics, Breeding, and Genetic Resources, pp. 282-298. Sinauer, Sunderland, MA.

NE1, M. 1987. Molecular and Evolutionary Genetics. Columbia University Press, New York.

PERRY, D. J. AND KNOWLES, P. 1991. Spatial genetic structure within three sugar maple (Acer saccharum Marsh.) stands. Heredity, 66, 137-142.

SAS INSTITUTE. 1985. SAS User's Guide: Statistical Version. 5th edn. SAS Institute, Cary, NC.

SHAPCOTT, A. 1995. The spatial genetic structure in natural populations of the Australian temperate rainforest tree Atherosperma moschatum. Heredity, 74, 28-38.

SLATK1N, M. AND ARTER, H. E. 1991a. Spatial autocorrelation methods in population genetics. Am. Nat., 138, $499-517$.

SLATKIN, M. AND ARTER, H. E. 1991b. Replay to Sokal and Oden. Am. Nat., 138, 522-523.

(c) The Genetical Society of Great Britain, Heredity, 77, 359-368. 
SOKAL, R. R. AND JACQUEZ, G. M. 1991. Testing inferences about microevolutionary process by means of spatial autocorrelation analysis. Evolution, 45, 152-168.

SOKAL, R. R. AND MENOZZ, P. 1982. Spatial autocorrelation of HLA frequencies in Europe support demic diffusion of early farmers. Am. Nat., 119, 1-17.

SOKAL, R. R. AND ODEN, N. L. 1978. Spatial autocorrelation in biology 1. Methodology. Biol. J. Linn. Soc., 10, 199-228.

SOKAL, R. R. AND ODEN, N. L. 1991. Spatial autocorrelation analysis as an inferential tool in population genetics. Am. Nat., 138, 518-521.

SOKAL, R. R. AND WARTENBERG, D. E. 1983. A test of spatial autocorrelation analysis using an isolationby-distance model. Genetics, 105, 219-237.

SOKAL, R. R., JACQUEZ, G. M. AND WOOTEN, M. C. 1989. Spatial autocorrelation analysis of migration and selection. Genetics, 121, 845-855.

WARtenberg, D. 1989. SAAP - A Spatial Autocorrelation Analysis Program. University of Medicine and Dentistry of New Jersey, Piscataway, NJ.

YOUNG, A. G. AND MERRIAM, H. G. 1994. Effects of forest fragmentation on the spatial genetic structure of Acer saccharum Marsh. (sugar maple) populations. Heredity, 72, 201-208. 